\title{
Influence of Intergeneric/Interspecies Mitochondrial Injection; Parthenogenetic Development of Bovine Oocytes after Injection of Mitochondria Derived from Somatic Cells
}

\author{
Kumiko TAKEDA ${ }^{1)}$, Kanokwan SRIRATTANA ${ }^{2)}$, Kazutsugu MATSUKAWA ${ }^{1,3)}$, Satoshi AKAGI ${ }^{1)}$, \\ Masahiro KANEDA ${ }^{1}$, Mariko TASAI $^{1)}$, Keijiro NIRASAWA ${ }^{1)}$, Carl A. PINKERT ${ }^{4}$, \\ Rangsun PARNPAI ${ }^{2)}$ and Takashi NAGAI) \\ 1) Institute of Livestock and Grassland Science, National Agriculture and Food Research Organization, Ibaraki 305-0901, \\ Japan \\ 2) Embryo Technology and Stem Cell Research Center and School of Biotechnology, Suranaree University of Technology, \\ Nakhon Ratchasima 30000, Thailand \\ 3) Research and Education Faculty, Kochi University, Kochi 783-8502, Japan \\ ${ }^{4)}$ College of Veterinary Medicine, Auburn University, AL 36849-5112, USA
}

\begin{abstract}
Interspecies/intergeneric mitochondrial heteroplasmy can occur in interspecies/intergeneric hybrid embryos or following nuclear transfer. In the present study, intergeneric buffalo (Bubalus bubalis) mitochondria (WB-mt) or interspecies murine (Mus spretus) mitochondria (M-mt) were injected into bovine (Bos taurus) oocytes, and the subsequent embryonic development was characterized. Fibroblast mitochondria (WB-mt or M-mt) were microinjected into in vitro matured bovine oocytes followed by oocyte activation by a combination of electrical stimulation and 6-dimethylaminopurine treatment. After seven days of culture, embryo development was evaluated. The copy number of specific mtDNA populations (introduced and native mtDNA) from heteroplasmic oocytes was estimated using real-time PCR. The results illustrated that oocytes injected with either WB-mt or M-mt can develop to the blastocyst stage (20.6\% and $19.6 \%$ ). Cleavage division rates and development to the morula stage in oocytes injected with WB-mt were lower (76.2\% and $45.9 \%$, respectively) in comparison with uninjected oocytes $(89.2 \%$ and $59.1 \%$, respectively) $(\mathrm{P}<0.05)$. However, no differences were found in comparing M-mt injected oocytes and controls $(\mathrm{P}>0.05)$. An increase in bovine mtDNA copy number was observed at the expanded blastocyst stage of injected embryos $(\mathrm{P}<0.01)$, while the number of injected mtDNA was stable throughout development. This study demonstrates that interspecies/intergeneric mitochondrial injected bovine oocytes have the ability to develop to the blastocyst stage after parthenogenetic activation and that injected mtDNA was neither selectively destroyed nor enhanced through development. Moreover, injected intergeneric mitochondria had a demonstrated influence on bovine parthenogenetic development and mtDNA replication.
\end{abstract}

Key words: Bovine oocyte, Mitochondria, Mouse, mtDNA, Water buffalo

(J. Reprod. Dev. 58: 323-329, 2012)

$\mathbf{S}$ omatic cell nuclear transfer (SCNT) offers the possibility of preserving endangered species, and SCNT has been applied to many mammalian species [1]. However, owing to the limited availability of oocytes from wild animals, the cloning of endangered species benefits from the use of recipient oocytes from a related domestic species. However, this methodology results in the production of nuclear-cytoplasmic hybrids $[2,3]$. Despite numerous attempts in a wide variety of species, the number of live births of cloned offspring is still limited in instances that combine genetic compartments of closely related species $[4,5]$. The generation of animals through interspecies/intergeneric SCNT (iSCNT) poses several problems including mitochondrial/genomic DNA incompatibility, embryonic

Received: October 21, 2011

Accepted: January 11, 2012

Published online in J-STAGE: March 9, 2012

(C2012 by the Society for Reproduction and Development Correspondence: K Takeda (e-mail: kumiko@affrc.go.jp) genome activation of the donor nucleus by the recipient oocyte, and availability of suitable foster mothers for iSCNT embryos. The species-specific nature of mitochondrial biogenesis and function makes this modeling particularly significant for iSCNT.

F1 hybrids and iSCNT live offspring obtained using river buffalo (Bubalus bubalis bubalis, $2 \mathrm{n}=50$ ) and swamp buffalo (Bubalus bubalis carabanesis, $2 \mathrm{n}=48$ ) have been reported [6,7]. Although $25.9 \%$ of hybrid embryos in bovine (Bos taurus, $2 \mathrm{n}=60$ ) oocytes exposed to water buffalo (Bubalus bubalis) sperm reached the blastocyst stage [8], attempts failed to obtain hybrid offspring $[9,10]$ with the exception of one rare case [11]. In a similar vein, buffalo-bovine iSCNT embryos demonstrated development to the blastocyst stage [12-14]; however, neither pregnancy nor natural delivery was reported.

In the process of SCNT, the transfer of donor cell mitochondria with nuclei into recipient oocytes resulted in mitochondrial heteroplasmy. Moreover, mitochondrial DNA (mtDNA) accompanying the donor cell was transmitted to offspring at varying but low 
abundance in comparison with recipient oocyte mtDNA [15-17]. The donor cell mtDNA copy numbers in buffalo-bovine iSCNT embryos were constant throughout the iSCNT process until arrest at the 8- to 16-cell stage [18]. Using other genetic combinations in creation of iSCNT embryos, varying levels of mtDNA heteroplasmy were observed [19-22]. In addition to heteroplasmy identification, mtDNA homoplasmy of recipient oocyte mtDNA was also found in a host of analyzed iSCNT offspring [23-27]. In these instances, the host oocyte nuclear backgrounds did not interfere with subsequent oocyte mtDNA replication.

During normal fertilization, the oocyte contributes all mitochondria to the developing embryo, while the sperm mitochondria are destroyed shortly after fertilization [28]. Maternal inheritance of mtDNA in mammals is a developmental paradox because the fertilizing spermatozoon introduces up to 100 functional mitochondria into the oocyte cytoplasm at fertilization. Destruction of sperm mitochondria appears to be an evolutionary and developmental advantage because the paternal mitochondria and their DNA may be compromised by the deleterious action of reactive oxygen species (ROS) encountered by sperm during spermatogenesis, storage, migration, and fertilization $[29,30]$. The ability to introduce exogenous mitochondria into mouse ova was initially used to study mitochondrial dynamics and mitochondrial heteroplasmy in vivo [31]. These models can be used to evaluate the biological significance and consequences of specific mitochondrial modifications and in various therapeutic modalities. Therefore, this modeling approach was employed to demonstrate that transferred somatic mitochondria dramatically influence parthenogenetic development of mammalian oocytes [32, 33].

To study the influence of intergeneric/interspecies mtDNA (imtDNA) transferred into oocytes, we investigated the developmental ability and mtDNA copy numbers during bovine (Bos taurus) parthenogenetic development using microinjected intergeneric (Bubalus bubalis) or interspecies (Mus spretus) mitochondria derived from somatic cells.

\section{Materials and Methods}

All reagents were purchased from Sigma-Aldrich (St. Louis, MO, USA) unless otherwise specified.

\section{Preparation of oocytes}

In vitro matured bovine oocytes were prepared as described previously [18, 33]. In brief, bovine (Bos taurus; Holstein or Japanese Black) oocytes collected from slaughterhouse-derived ovaries were cultured in vitro for $24 \mathrm{~h}$ at $38.5 \mathrm{C}$ under a humidified atmosphere of 5\% $\mathrm{CO}_{2}$ in air in Medium 199 (Gibco, Invitrogen, Carlsbad, CA, USA) supplemented with $10 \%$ fetal bovine serum (FBS, HyClone, Logan, UT, USA). After maturation in culture, oocytes were treated with $0.2 \%$ bovine testicular hyaluronidase (Type I-S, 359 units $/ \mathrm{mg}$ ) in M2 medium to dissociate cumulus cells.

\section{Donor mitochondrial preparation, injection and oocyte activation}

Primary cultured fibroblasts were established from biopsied ear epithelium from a 5-year-old male water buffalo (swamp type;
Bubalus bubalis) as previously described [34] and frozen using a commercially available freezing solution (CELLBANKER, Nippon Zenyaku Kogyo, Fukushima, Japan).

Inbred Mus spretus mice (SPRET/Ei) purchased from The Jackson Laboratory were used as mitochondrial donors. Primary cell cultures were established from ear epithelium as previously described [32].

Frozen-thawed buffalo or murine fibroblast cells were prepared at confluency in D-MEM (Gibco, Invitrogen) supplemented with $10 \%$ FBS and $1 \mathrm{X}$ antibiotic-antimycotic solution (100 units $/ \mathrm{ml}$ penicillin $\mathrm{G}, 0.1 \mathrm{mg} / \mathrm{ml}$ streptomycin and $0.25 \mu \mathrm{g} / \mathrm{ml}$ amphotericin B) (Fig. 1A). Mitochondria were isolated from cells by differential centrifugation. Isolated mitochondria (water buffalo mitochondria (Fig 1B), WB-mt, or murine mitochondria, M-mt) were microinjected into oocytes as previously described $[32,33]$. Briefly, mitochondrial pellets were resuspended in respiration buffer $(225 \mathrm{mM}$ mannitol, $75 \mathrm{mM}$ sucrose, $10 \mathrm{mM} \mathrm{KCl}, 10 \mathrm{mM}$ Tris- $\mathrm{HCl}, 5 \mathrm{mM} \mathrm{KH}_{2} \mathrm{PO}_{4}, \mathrm{pH}$ 7.2), and, approximately 1-2 pl of mitochondrial suspensions were injected into oocytes using a Piezo micromanipulator (Prime-Tech, Tsuchiura, Japan) (Fig. 1C-D).

To examine the success of mitochondrial microinjection, confluent cultures were incubated in DMEM $+10 \%$ FBS containing $200 \mathrm{nM}$ MitoTracker ${ }^{\mathrm{TM}}$ Green FM (Molecular Probes, Eugene, OR, USA) and $10 \mu \mathrm{g} / \mathrm{ml}$ cytochalasin B for $20 \mathrm{~min}$ at $37 \mathrm{C}$. Fluorescence-labeled mitochondria were detected after injections using fluorescence microscopy (TE300; Nikon, Tokyo, Japan) with a B-2A filter set (excitation 450-490 nm, bandpass; emission $520 \mathrm{~nm}$, longpass) (Fig. 1D').

Surviving oocytes, 15-30 min after mitochondrial microinjection, were activated using a double DC pulse of $57 \mathrm{~V} / \mathrm{mm}$ for $50 \mu \mathrm{sec}$ in Zimmerman's mammalian cell fusion medium and cultured in Medium 199 containing $0.4 \mathrm{mg} / \mathrm{ml}$ 6DMAP and 10\% FBS for $5 \mathrm{~h}$. Oocytes were washed and cultured in IVD101 medium (Research Institute for Functional Peptides, Yamagata, Japan) [35] for 7 days at $38.5 \mathrm{C}$ under $5 \% \mathrm{O}_{2}, 5 \% \mathrm{CO}_{2}$ and $90 \% \mathrm{~N}_{2}$. Differences in developmental rates were calculated using Chi-squared analysis. The critical threshold value was derived by application of a Bonferroni correction. Differences were defined as $\mathrm{P}<0.05$.

\section{Quantification of bovine mtDNA and buffalo $m t D N A$ in bovine oocytes and embryos}

Oocytes were randomly selected at various stages: after injection of mitochondria, electrical stimulation, chemical activation, and 7 days of culture. Post culture, oocytes were washed six times in PBS supplemented with $1 \%$ polyvinylpyrrolidone. Individual embryos were placed into $1.5 \mathrm{ml}$ siliconized microcentrifuge tubes (Assist, Tokyo, Japan) containing $10 \mu \mathrm{l}$ of sterile distilled water and frozen at $-80 \mathrm{C}$ until DNA extraction. Total DNA was extracted from individual embryos using a QIAamp DNA Micro Kit (Qiagen, Mannheim, Germany) [36]. The species-specific quantification of bovine (BO) and water buffalo (WB) mtDNA was as previously described [18]. Briefly, quantification analysis was performed using a LightCycler system (Roche Diagnostics GmbH, Mannheim,

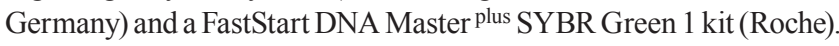
Species-specific primers were designed from the cytochrome b (Cyt b) region of bovine and buffalo mitochondrial genomes [18, 33]. 

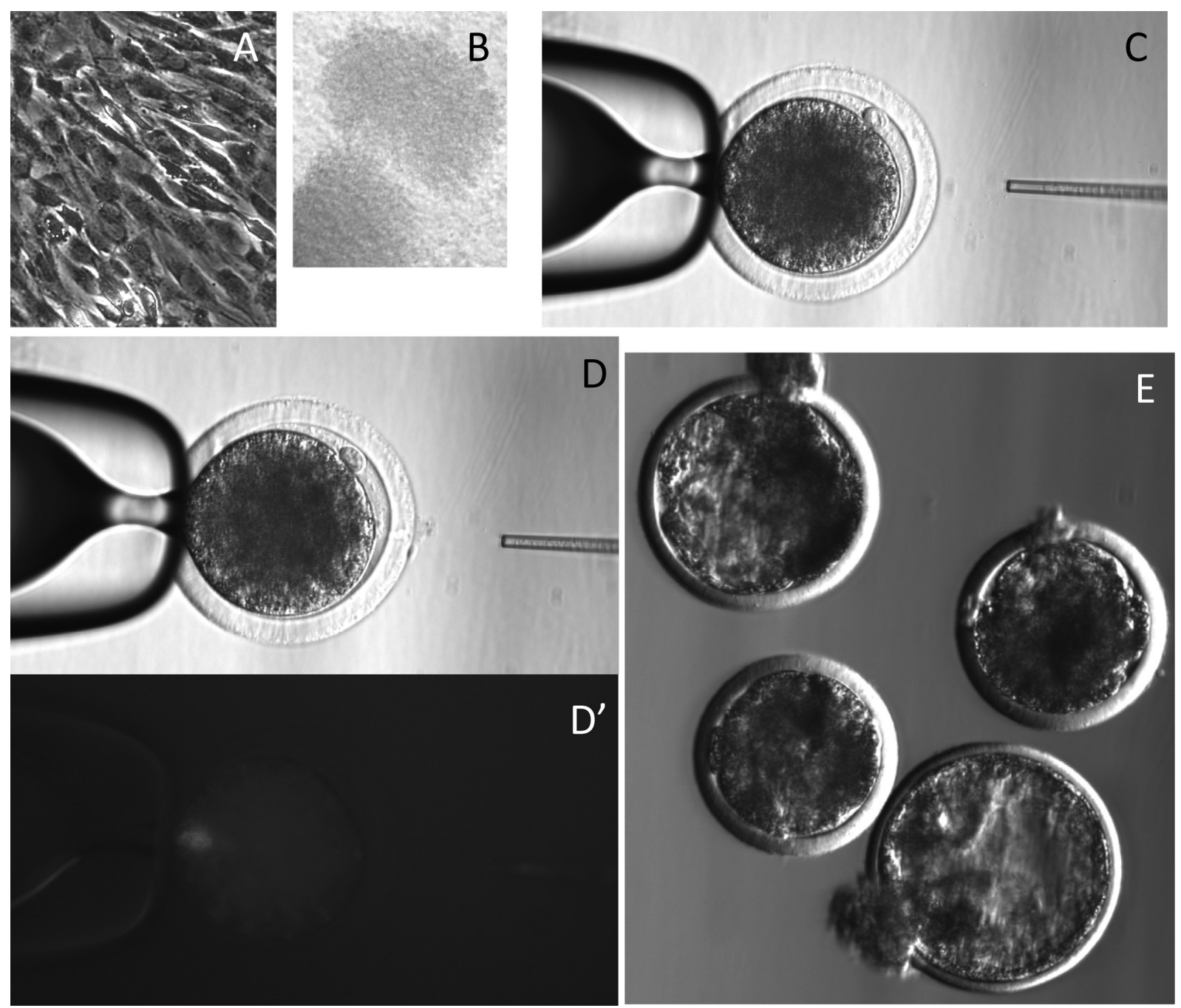

Fig. 1. Microinjection of buffalo mitochondria (WB-mt, B) obtained from buffalo cells (A) into bovine oocytes (C-D) and the parthenogenetic development. Fluorescence-labeled mitochondria were detected after injections using fluorescence microscopy (TE300) with a B-2A filter (D'). Some of the WB-mt-injected bovine oocytes could develop to the blastocyst stage (E).

Specific amplification was carried out with initial denaturation at $95 \mathrm{C}$ for $7 \mathrm{~min}$ followed by 45 (WB) or 40 (BO) cycles at $95 \mathrm{C}$ for $1 \mathrm{sec}, 60 \mathrm{C}$ (WB) or $55 \mathrm{C}$ (BO) for $5 \mathrm{sec}$ and $72 \mathrm{C}$ for $13 \mathrm{sec}$. Each mtDNA sample was analyzed twice to obtain a mean mtDNA copy number. Differences in mtDNA copy number per embryo during development was analyzed by one-way ANOVA, and then differences in mtDNA copy numbers between treatments or at different developmental stages were compared using the Student's $t$-test with Bonferroni correction $(\mathrm{P}<0.05)$.

Quantification of bovine mtDNA and murine mtDNA in bovine oocytes and embryos

The oocytes were randomly selected after injection of M-mt and 7 days of culture. Total DNA was extracted from individual embryos as described for WB-mt injected embryos. Species-specific real-time PCR was performed as previously described [33]. Briefly, quantification analysis was performed using a LightCycler sys-

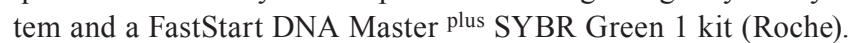
Specific amplification was carried out with initial denaturation at $95 \mathrm{C}$ for 7 min followed by 45 cycles of at $95 \mathrm{C}$ for $1 \mathrm{sec}, 61 \mathrm{C}(\mathrm{M})$ or $55 \mathrm{C}(\mathrm{BO})$ for $5 \mathrm{sec}$ and $72 \mathrm{C}$ for $13 \mathrm{sec}$. Each mtDNA sample was analyzed in duplicate to obtain an average number of mtDNA molecules. mtDNA copy numbers per embryo during development were analyzed by one-way ANOVA $(\mathrm{P}<0.05)$.

\section{Animal use}

All procedures and experiments were performed according to protocols approved by the NILGS Laboratory Animal Experimental Guide and the Japanese Prime Minister's Office of Laboratory Animal Welfare (No. 6, 1980). 
Table 1. Parthenogenetic development of bovine oocytes injected with water buffalo mitochondria (WB-mt)

\begin{tabular}{lcccr}
\hline \multirow{2}{*}{$\begin{array}{c}\text { Source of injection } \\
\text { (No. of replicates) }\end{array}$} & $\begin{array}{c}\text { Survival post } \\
\text { activation }^{\mathrm{a}}\end{array}$ & \multicolumn{3}{c}{ Development (\%) } \\
\cline { 3 - 5 } & 281 & $214(76.2)^{\mathrm{b}}$ & $129(45.9)^{\mathrm{b}}$ & $58(20.6)$ \\
\hline WB-mt (11) & 174 & $148(85.1)^{\mathrm{c}}$ & $88(50.6)^{\mathrm{bc}}$ & $46(26.4)$ \\
Respiration buffer (11) & 186 & $166(89.2)^{\mathrm{c}}$ & $110(59.1)^{\mathrm{c}}$ & $50(26.9)$ \\
\hline
\end{tabular}

a The total number of oocytes incubated after activation. ${ }^{b, c}$ Within a parameter, values are significantly different $(\mathrm{P}<0.05)$.

Table 2. Bovine and buffalo mtDNA copy number in bovine oocytes injected with water buffalo mitochondria (WB-mt)

\begin{tabular}{|c|c|c|c|c|}
\hline \multirow{2}{*}{$\begin{array}{l}\text { Timing and stage of embryos } \\
\text { for examination }\end{array}$} & \multirow{2}{*}{$\begin{array}{l}\text { No. of embryos } \\
\text { analyzed }\end{array}$} & \multicolumn{2}{|c|}{ Average ( \pm SD) copy number of mtDNA } & \multirow{2}{*}{$\begin{array}{l}\text { WB mtDNA } \\
\%\end{array}$} \\
\hline & & BO $\left(10^{5}\right.$ copies $)$ & WB $\left(10^{2}\right.$ copies $)$ & \\
\hline After injection & 26 & $8.4 \pm 3.4^{\mathrm{ac}}$ & $5.8 \pm 4.3$ & $0.08^{\mathrm{a}}$ \\
\hline After pulse & 10 & $5.1 \pm 1.0^{\mathrm{b}}$ & $4.3 \pm 2.2$ & $0.09^{\mathrm{a}}$ \\
\hline After 6DMAP & 15 & $6.2 \pm 0.8^{\mathrm{c}}$ & $4.3 \pm 6.5$ & $0.07^{a b}$ \\
\hline Arrested at morula & 20 & $8.9 \pm 3.4$ ad & $4.0 \pm 3.2$ & $0.06^{\mathrm{ab}}$ \\
\hline Blastocyst & 21 & $9.4 \pm 3.3^{\text {ad }}$ & $2.7 \pm 2.4$ & $0.03^{b}$ \\
\hline Expanded blastocyst & 19 & $10.8 \pm 4.0^{\mathrm{d}}$ & $6.2 \pm 6.3$ & $0.06^{\mathrm{ab}}$ \\
\hline
\end{tabular}

a,b,c,d Within a parameter, values are significantly different $(\mathrm{P}<0.05)$. After injection: after WB-mt injection. After pulse: after electric stimulation. After 6DMAP: after chemical activation by 6DMAP. BO: bovine. WB: water buffalo.

\section{Results}

\section{Development of bovine oocytes microinjected with water}

\section{buffalo mitochondria}

To study influences of intergeneric exogenous mitochondria on parthenogenetic development of bovine oocytes, oocytes were microinjected with mitochondrial fractions derived from water buffalo ear propagated cells. Fluorescence-labeled mitochondria were observed in the oocytes after mitochondrial injection (Fig. 1D').

WB-mt were injected into bovine oocytes $(n=281)$, which showed a lower rate of cleavage $(76.2 \%)$ when compared with oocytes injected with buffer or uninjected controls $(85.1 \%$ and $89.2 \%$, respectively, $\mathrm{P}<0.05$, Table 1). Some WB-mt injected oocytes developed to the blastocyst stage (Fig. 1E). The developmental rate of blastocyst formation was not different between oocytes injected with WB-mt (20.6\%) and oocytes injected with buffer or uninjected oocytes $(26.4 \%$ and $26.9 \%$, respectively, $\mathrm{P}>0.05$ ). However, the developmental rate of morula formation was lower in oocytes injected with WB-mt (45.9\%) when compared with uninjected oocytes $(59.1 \%, \mathrm{P}<0.05)$.

\section{Quantification of bovine mtDNA and exogenous buffalo $m t D N A$ in bovine oocytes}

The bovine and buffalo mtDNA content in WB-mt injected oocytes was analyzed after mitochondrial injection, after electric stimulation, after chemical activation, and after 7 days of culture. The oocyte (BO) mtDNA copy numbers in WB-mt injected oocytes were significantly decreased after electric stimulation and then increased following 7 days of incubation $(\mathrm{P}<0.05$; Table 2). After electric stimulation and at the expanded blastocyst stage, the $\mathrm{BO}$ mtDNA copy number in WB-mt injected oocytes was lower than in uninjected controls $(\mathrm{P}<0.05$, Fig. 2$)$. The copy numbers of bovine
( $\times 10^{5}$ copies)

WB-mt ij

- Buffer ij

$\square$ Uninjected

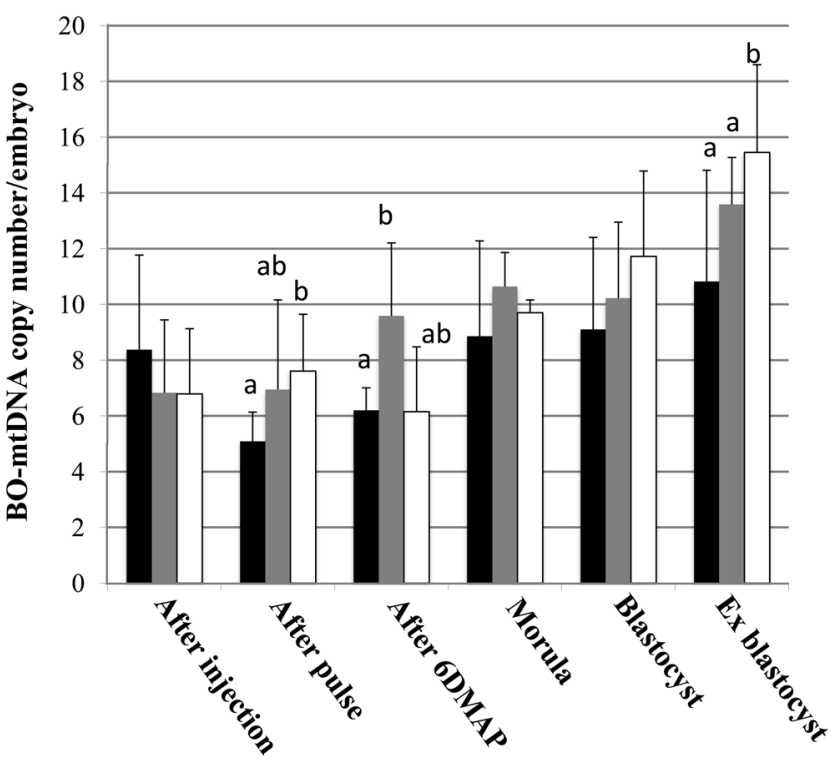

Fig. 2. Bovine (BO) mtDNA copy number per bovine oocyte/embryo injected with water buffalo (WB) mitochondria. Oocytes/ embryos injected with WB-mt or buffer or that were uninjected (after injection) were analyzed after electric stimulation (after pulse), chemical activation by 6DMAP (after 6DMAP) and 7 days of culture (arrested at the morula, blastocyst, expanded (Ex) blastocyst stage). a,b Superscripts represent differences among treatments, at each individual stage, analyzed by the Student's $t$-test $(\mathrm{P}<0.05)$. 
mtDNA in WB-mt injected blastocysts $\left(9.4 \pm 3.3 \times 10^{5}\right)$ or expanded blastocysts $\left(10.8 \pm 4.0 \times 10^{5}\right)$ were not different from those in oocytes arrested at the morula stage $\left(8.9 \pm 3.4 \times 10^{5}, \mathrm{P}>0.05\right.$, Table 2). In contrast, exogeous (WB) mtDNA copy numbers in WB-mt injected oocytes were constant throughout development until the expanded blastocyst stage (Fig. 3).

\section{Development of bovine oocytes microinjected with murine mitochondria}

After M-mt injection into bovine oocytes ( $\mathrm{n}=102)$, developmental rates were not different between oocytes injected with M-mt and oocytes injected with buffer or uninjected oocytes (Table 3).

\section{Quantification of bovine mtDNA and exogenous murine $m t D N A$ in bovine oocytes}

Bovine and murine mtDNA content in oocytes injected with M-mt was $8.1 \pm 2.6 \times 10^{5}$ and $6.1 \pm 11.1 \times 10^{2}$, respectively (Table 4). There was no difference in bovine and murine mtDNA copy numbers in arrested morulae $\left(7.8 \pm 0.7 \times 10^{5}\right.$ and $6.3 \pm 3.9 \times 10^{2}$, respectively) and blastocysts $\left(9.3 \pm 2.6 \times 10^{5}\right.$ and $3.8 \pm 4.7 \times 10^{2}$, respectively) when compared with those of injected oocytes.

\section{Discussion}

Previously, injection of foreign (exogenous) mitochondria into pronuclear zygotes resulted in the production of heteroplasmic mice [31, 37, 38]. Mitochondrial injection models can be used to evaluate the biological significance and consequences of specific mitochondrial modifications. These models are important in our understanding of the complex interactions between intergeneric/ interspecies exogenous mitochondria and recipient nuclei and mitochondria in early development. Previous reports demonstrated that exogenous mitochondria originating from donor cells directly affected murine parthenogenetic development [32, 33]. Similarly, this study found that intergeneric somatic mitochondria influenced

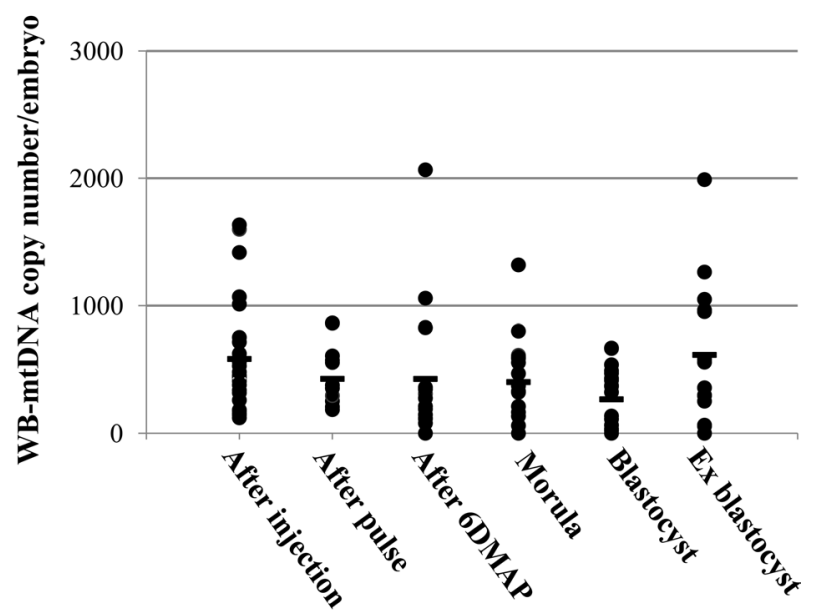

Fig. 3. Water buffalo (WB) mtDNA copy number per oocyte/ embryo injected with water buffalo (WB) mitochondria Oocytes/embryos were analyzed after WB-mt injection (after injection), electric stimulation (after pulse), chemical activation by 6DMAP (after 6DMAP) and after 7 days of culture (arrested at morula, blastocyst, expanded (Ex) blastocyst stage). Bars represent the average mtDNA copy number. MtDNA copy number per embryo showed no difference during development analyzed by one-way ANOVA $(\mathrm{P}=0.11)$.

the rate and success of bovine parthenogenetic development. A decreased developmental rate through the morula stage was shown in WB-mt injected oocytes, although no differences in developmental rate were found between $\mathrm{M}-\mathrm{mt}$ injected oocytes. These results raise the possibility that the interspecies mitochondria also affected bovine parthenogenetic development.

Alteration of mtDNA copy numbers has been observed during bovine early development $[15,39]$. Interestingly, the increase in

Table 3. Parthenogenetic development of bovine oocytes injected with murine mitochondria (M-mt)

\begin{tabular}{lcccc}
\hline \multirow{2}{*}{$\begin{array}{c}\text { Source for injection } \\
\text { (No. of replicates) }\end{array}$} & $\begin{array}{c}\text { Survival post } \\
\text { activation }^{\text {a }}\end{array}$ & Cleaved & Morula & Blastocyst \\
\cline { 3 - 5 } & 102 & $80(78.4)$ & $45(44.1)$ & $20(19.6)$ \\
M-mt (5) & 94 & $77(81.9)$ & $52(55.3)$ & $23(24.5)$ \\
Respiration buffer (5) & 44 & $39(88.6)$ & $22(50.0)$ & $10(22.7)$ \\
Uninjected (3) & & &
\end{tabular}

${ }^{a}$ The total number of oocytes incubated after activation. There are no significant differences within a parameter $(\mathrm{P}>0.05)$.

Table 4. Bovine and murine mtDNA copy number in bovine oocytes injected with murine mitochondria (M-mt)

\begin{tabular}{lcccc}
\hline \multirow{2}{*}{$\begin{array}{c}\text { Timing and stage of } \\
\text { embryos for examination }\end{array}$} & $\begin{array}{c}\text { No. of embryos } \\
\text { analyzed }\end{array}$ & \multicolumn{2}{c}{ Average $( \pm \mathrm{SD})$ copy number of mtDNA } & \multirow{2}{*}{ M mtDNA\% } \\
\cline { 3 - 4 } After injection & 11 & $8.1 \pm 2.6$ & $6.1 \pm 11.1$ & 0.08 \\
Arrested at morula & 10 & $7.8 \pm 0.7$ & $6.3 \pm 3.9$ & 0.08 \\
Blastocyst & 8 & $9.3 \pm 2.6$ & $3.8 \pm 4.7$ & 0.04 \\
\hline
\end{tabular}

There are no significant differences within a parameter $(\mathrm{P}>0.05)$. After injection: after $\mathrm{M}$-mt injection. BO: bovine. M: murine. 
copy number at the blastocyst stage was similar to that in bovine embryos derived from in vitro fertilization $[15,40]$. The mtDNA copy number can provide one index for normal embryonic development; therefore, one could surmise that nuclear function was affected in these embryos. Additionally, our results illustrated that exogeous interspecies/intergeneric mtDNA injected into oocytes were not selectively destroyed; indeed, they were maintained throughout the early development. In iSCNT embryos, constant copy numbers of donor somatic cell mtDNA from the 1-cell to the 8-cell stage were also found in water buffalo-bovine [18], sheep-bovine [20], cat-bovine [21], goat-sheep [22], and macaque-rabbit [17] arrested embryos. Sperm mitochondria destruction is induced by a process related to the ubiquitin-proteasome pathway in fertilization [30, 41]. The dramatic reduction of mtDNA content argues in favor of active destruction rather than a reduced turnover of mtDNA molecules [40]. Moreover, paternal mtDNA was detected only through the early pronucleus stage in intraspecific hybrids of Mus musculus. In contrast, paternal mtDNA was detected throughout development, from the pronucleus stage through to neonates, in interspecific hybrids between Mus musculus and Mus spretus [42]. It is doubtful that exogenous intergeneric or somatic cell mitochondria would not be recognized by recipient cellular surveillance from mitophagy to the ubiquitin-proteasome pathway observed in sperm mitochondria. Interestingly, buffalo ooplasm transfer into bovine zygotes by fusion methodology introduced $8.3 \%$ of buffalo mtDNA and maintained a comparable ratio through to the blastocyst stage. However, no vestiges of buffalo mtDNA were found in subsequent offspring [43]. This would support an inability of buffalo mtDNA to establish a functional interaction with the bovine nucleus. In another report, donor embryonic cell mtDNA was markedly decreased during embryo development and eliminated in the majority of offspring derived from bovine-bovine embryonic nuclear transfer technology [44]. Sheep-goat iSCNT embryos also showed a loss of donor mtDNA during development [22]. From our results, injected WB-mtDNA copy numbers were stable, while the bovine mtDNA increased after the morula stage (Table 2). The i-mtDNA was not selectively destroyed following either WB-mt or M-mt injection. In one other study, gaur-bovine iSCNT embryos showed an increase in donor (gaur) mtDNA copy number at the blastocyst stage [45]. Indeed, the need to exclude defective exogenous mtDNA from the developing embryo does represent a major biological selective pressure against survival of exogenous mtDNA.

An attempt at iSCNT using gaur (Bos gaurus) donor cell and domestic bovine (Bos taurus) recipient oocytes produced several pregnancies and a single offspring [23]. In addition, reconstructed embryos resulting from iSCNT between water buffalo (Bubalus bubalis) and domestic bovine developed to the blastocyst stage [14] but did not result in production of term fetuses or offspring. As epigenetic reprogramming of the donor nucleus from its differentiated status to a totipotent state in the presence of interspecies ooplasm requires an elaborate interplay between the nucleus and the ooplasm [45]. This orchestrated interaction requires the involvement of many nuclear-encoded proteins with the displacement loop (D-loop) of the mtDNA genome to mediate replication and transcription efficiently [46], regulation of total mtDNA copy numbers [47] and supply of ATP for energy requiring activities
$[48,49]$. The results of this study illustrate that characteristic and complex mitochondrial-nuclear interactions are affected during early parthenogenetic development.

In conclusion, intergeneric/interspecies mitochondria injected into bovine oocytes provide oocytes the ability to develop to the blastocyst stage after parthenogenetic activation. Injected i-mtDNA was not selectively destroyed or increased throughout development. Moreover, injected intergeneric mitochondria influence bovine parthenogenetic development and mtDNA replication- illustrating an important consideration in developing these and related reproductive technologies.

\section{Acknowledgments}

We thank Prof Y Kanai (University of Tsukuba), Dr M Iwamoto (Prime Tech) and Dr Y Kameyama (Tokyo University of Agriculture) for their assistance and consideration. This work was supported by a grant from the National Agriculture and Food Research Organization of Japan, the Thailand Research Fund, Suranaree University of Technology and the Japan Society for the Promotion of Science - National Research Council of Thailand (JSPS-NRCT) scientific cooperation program.

\section{References}

1. Campbell KH, Fisher P, Chen WC, Choi I, Kelly RD, Lee JH, Xhu J. Somatic cell nuclear transfer: Past, present and future perspectives. Theriogenology 2007; 68(Suppl 1): S214-S231. [Medline] [CrossRef]

2. Gómez MC, Pope CE, Ricks DM, Lyons J, Dumas C, Dresser BL. Cloning endangered felids using heterospecific donor oocytes and interspecies embryo transfer Reprod Fertil Dev 2009; 21: 76-82. [Medline] [CrossRef]

3. Loi P, Modlinski JA, Ptak G. Interspecies somatic cell nuclear transfer: a salvage tool seeking first aid. Theriogenology 2011; 76: 217-228. [Medline] [CrossRef]

4. Loi P, Galli C, Ptak G. Cloning of endangered mammalian species: any progress? Trends Biotechnol 2007; 25: 195-200. [Medline] [CrossRef]

5. Owiny OD, Barry DM, Agaba M, Godke RA. In vitro production of cattle x buffalo hybrid embryos using cattle oocytes and African buffalo (Syncerus caffer caffer) epididymal sperm. Theriogenology 2009; 71: 884-894. [Medline] [CrossRef]

6. Bongso TA, Hilmi M. Chromosome banding homologies of a tandem fusion in river, swamp, and crossbred buffaloes (Bubalus bubalis). Can J Genet Cytol 1982; 24: 667673

7. Yang CY, Li RC, Pang CY, Yang BZ, Qin GS, Chen MT, Zhang XF, Huang FX, Zheng HY, Huang YJ, Liang XW. Study on the inter-subspecies nuclear transfer of river buffalo somatic cell nuclei into swamp buffalo oocyte cytoplasm. Anim Reprod Sci 2010; 121: 78-83. [Medline] [CrossRef]

8. Kochhar HP, Rao KB, Luciano AM, Totey SM, Gandolfi F, Basrur PK, King WA. In vitro production of cattle-water buffalo (Bos taurus--Bubalus bubalis) hybrid embryos. Zygote 2002; 10: 155-162. [Medline] [CrossRef]

9. Tatham BG. Increasing Buffalo Production using Reproduction Technology: A Report for the Rural Industries Research and Development Corporation. RIRDC Publications; 2000: 00/165.

10. Patil S, Totey S. Developmental failure of hybrid embryos generated by in vitro fertilization of water buffalo (Bubalus bubalis) oocyte with bovine spermatozoa. Mol Reprod Dev 2003; 64: 360-368. [Medline] [CrossRef]

11. Mason IL. Genetics. In: Cockrill WR (ed.), The Husbandry and Health of the Domestic Buffalo. UN: FAO Rome; 1974: 57-81.

12. Kitiyanant Y, Saikhun J, Chaisalee B, White KL, Pavasuthipaisit K. Somatic cell cloning in Buffalo (Bubalus bubalis): effects of interspecies cytoplasmic recipients and activation procedures. Cloning Stem Cells 2001; 3: 97-104. [Medline] [CrossRef]

13. Saikhun J, Pavasuthipaisit K, Jaruansuwan M, Kitiyanant $\mathbf{Y}$. Xenonuclear transplantation of buffalo (Bubalus bubalis) fetal and adult somatic cell nuclei into bovine (Bos indicus) oocyte cytoplasm and their subsequent development. Theriogenology 2002; 57: 1829-1837. [Medline] [CrossRef]

14. Lu F, Shi D, Wei J, Yang S, Wei Y. Development of embryos reconstructed by in- 
terspecies nuclear transfer of adult fibroblasts between buffalo (Bubalus bubalis) and cattle (Bos indicus). Theriogenology 2005; 64: 1309-1319. [Medline] [CrossRef]

15. Smith LC, Thundathil J, Filion F. Role of the mitochondrial genome in preimplantation development and assisted reproductive technologies. Reprod Fertil Dev 2005; 17: 15-22. [Medline] [CrossRef]

16. Hiendleder S. Mitochondrial DNA inheritance after SCNT. Adv Exp Med Biol 2007; 591: 103-116. [Medline] [CrossRef]

17. St John JC, Facucho-Oliveira J, Jiang Y, Kelly R, Salah R. Mitochondrial DNA transmission, replication and inheritance: a journey from the gamete through the embryo and into offspring and embryonic stem cells. Hum Reprod Update 2010; 16: 488-509. [Medline] [CrossRef]

18. Srirattana K, Matsukawa K, Akagi S, Tasai M, Tagami T, Nirasawa K, Nagai T, Kanai Y, Parnpai R, Takeda K. Constant transmission of mitochondrial DNA in intergeneric cloned embryos reconstructed from swamp buffalo fibroblasts and bovine ooplasm. Animal Science Journal 2011; 82: 236-243. [Medline] [CrossRef]

19. Yang CX, Kou ZH, Wang K, Jiang Y, Mao WW, Sun QY, Sheng HZ, Chen DY. Quantitative analysis of mitochondrial DNAs in macaque embryos reprogrammed by rabbit oocytes. Reproduction 2004; 127: 201-205. [Medline] [CrossRef]

20. Hua S, Zhang Y, Song K, Song J, Zhang Z, Zhang L, Zhang C, Cao J, Ma L. Development of bovine-ovine interspecies cloned embryos and mitochondria segregation in blastomeres during preimplantation. Anim Reprod Sci 2008; 105: 245-257. [Medline] [CrossRef]

21. Thongphakdee A, Kobayashi S, Imai K, Inaba Y, Tasai M, Tagami T, Nirasawa K, Nagai T, Saito N, Techakumphu M, Takeda K. Interspecies nuclear transfer embryos reconstructed from cat somatic cells and bovine ooplasm. J Reprod Dev 2008; 54: 142-147. [Medline] [CrossRef]

22. Ma LB, Yang L, Hua S, Cao JW, Li JX, Zhang Y. Development in vitro and mitochondrial fate of interspecies cloned embryos. Reprod Domest Anim 2008; 43: 279-285. [Medline] [CrossRef]

23. Lanza RP, Cibelli JB, Diaz F, Moraes CT, Farin PW, Farin CE, Hammer CJ, West MD, Damiani P. Cloning of an endangered species (Bos gaurus) using interspecies nuclear transfer. Cloning 2000; 2: 79-90. [Medline] [CrossRef]

24. Loi P, Ptak G, Barboni B, Fulka J Jr, Cappai P, Clinton M. Genetic rescue of an endangered mammal by cross-species nuclear transfer using post-mortem somatic cells. Nat Biotechnol 2001; 19: 962-964. [Medline] [CrossRef]

25. Meirelles FV, Bordignon V, Watanabe Y, Watanabe M, Dayan A, Lobo RB, Garcia JM, Smith LC. Complete replacement of the mitochondrial genotype in a Bos indicus calf reconstructed by nuclear transfer to a Bos taurus oocyte. Genetics 2001; 158: 351-356. [Medline]

26. Steinborn R, Schinogl P, Wells DN, Bergthaler A, Muller M, Brem G. Coexistence of Bos taurus and B. indicus mitochondrial DNAs in nuclear transfer-derived somatic cattle clones. Genetics 2002; 162: 823-829. [Medline]

27. Kim MK, Jang G, Oh HJ, Yuda F, Kim HJ, Hwang WS, Hossein MS, Kim JJ, Shin NS, Kang SK, Lee BC. Endangered wolves cloned from adult somatic cells. Cloning Stem Cells 2007; 9: 130-137. [Medline] [CrossRef]

28. Sutovsky P, Moreno RD, Ramalho-Santos J, Dominko T, Simerly C, Schatten G. Ubiquitin tag for sperm mitochondria. Nature 1999; 402: 371-372. [Medline] [CrossRef]

29. Cummins JM, Wakayama T, Yanagimachi R. Fate of microinjected spermatid mitochondria in the mouse oocyte and embryo. Zygote 1998; 6: 213-222. [Medline] [CrossRef]

30. Sutovsky P, Van Leyen K, McCauley T, Day BN, Sutovsky M. Degradation of paternal mitochondria after fertilization: implications for heteroplasmy, assisted reproductive technologies and mtDNA inheritance. Reprod Biomed Online 2004; 8: 24-33. [Medline] [CrossRef]

31. Pinkert CA, Smith LC, Trounce IA. Transgenic animals: Mitochondrial genome modification. In: Ullrey DE, Baer CK, Pond WG (eds.), Encyclopedia of Animal Science, vol. 2nd ed. New York: Dekkar, Taylor \& Francis; 2010: 1044-1046.
32. Takeda K, Tasai M, Iwamoto M, Onishi A, Tagami T, Nirasawa K, Hanada $\mathbf{H}$, Pinkert CA. Microinjection of cytoplasm or mitochondria derived from somatic cells affects parthenogenetic development of murine oocytes. Biol Reprod 2005; 72: 1397-1404. [Medline] [CrossRef]

33. Takeda K, Tasai M, Akagi S, Matsukawa K, Takahashi S, Iwamoto M, Srirattana K, Onishi A, Tagami T, Nirasawa K, Hanada H, Pinkert CA. Microinjection of serum-starved mitochondria derived from somatic cells affects parthenogenetic development of bovine and murine oocytes. Mitochondrion 2010; 10: 137-142. [Medline] [CrossRef]

34. Atabay EC, Takahashi Y, Katagiri S, Nagano M, Koga A, Kanai Y. Vitrification of bovine oocytes and its application to intergeneric somatic cell nucleus transfer. Theriogenology 2004; 61: 15-23. [Medline] [CrossRef]

35. Hoshi H. In vitro production of bovine embryos and their application for embryo transfer. Theriogenology 2003; 59: 675-685. [Medline] [CrossRef]

36. Kameyama Y, Filion F, Yoo JG, Smith LC. Characterization of mitochondrial replication and transcription control during rat early development in vivo and in vitro. Reproduction 2007; 133: 423-432. [Medline] [CrossRef]

37. Irwin MH, Johnson LW, Pinkert CA. Isolation and microinjection of somatic cellderived mitochondria and germline heteroplasmy in transmitochondrial mice. Transgenic Res 1999; 8: 119-123. [Medline] [CrossRef]

38. Ingraham CA, Pinkert CA. Developmental fate of mitochondria microinjected into murine zygotes. Mitochondrion 2003; 3: 39-46. [Medline] [CrossRef]

39. Tamassia M, Nuttinck F, May-Panloup P, Reynier P, Heyman Y, Charpigny G, Stojkovic M, Hiendleder S, Renard JP, Chastant-Maillard S. In vitro embryo production efficiency in cattle and its association with oocyte adenosine triphosphate content, quantity of mitochondrial DNA, and mitochondrial DNA haplogroup. Biol Reprod 2004; 71: 697-704. [Medline] [CrossRef]

40. May-Panloup P, Vignon X, Chretien MF, Heyman Y, Tamassia M, Malthiery Y, Reynier P. Increase of mitochondrial DNA content and transcripts in early bovine embryogenesis associated with upregulation of mtTFA and NRF1 transcription factors. Reprod Biol Endocrinol 2005; 3: 65. [Medline] [CrossRef]

41. Schatten H, Prather RS, Sun QY. The significance of mitochondria for embryo development in cloned farm animals. Mitochondrion 2005; 5: 303-321. [Medline] [CrossRef]

42. Kaneda H, Hayashi J, Takahama S, Taya C, Lindahl KF, Yonekawa H. Elimination of paternal mitochondrial DNA in intraspecific crosses during early mouse embryogenesis. Proc Natl Acad Sci U S A 1995; 92: 4542-4546. [Medline] [CrossRef]

43. Chiaratti MR, Ferreira CR, Perecin F, Meo SC, Sangalli JR, Mesquita LG, de Carvalho Balieiro JC, Smith LC, Garcia JM, Meirelles FV. Ooplast-mediated developmental rescue of bovine oocytes exposed to ethidium bromide. Reprod Biomed Online 2011; 22: 172-183. [Medline] [CrossRef]

44. Takeda K, Takahashi S, Onishi A, Goto Y, Miyazawa A, Imai H. Dominant distribution of mitochondrial DNA from recipient oocytes in bovine embryos and offspring after nuclear transfer. J Reprod Fertil 1999; 116: 253-259. [Medline] [CrossRef]

45. Mastromonaco GF, Favetta LA, Smith LC, Filion F, King WA. The influence of nuclear content on developmental competence of gaur $\mathrm{x}$ cattle hybrid in vitro fertilized and somatic cell nuclear transfer embryos. Biol Reprod 2007; 76: 514-523. [Medline] [CrossRef]

46. Taanman JW. The mitochondrial genome: structure, transcription, translation and replication. Biochim Biophys Acta 1999; 1410: 103-123. [Medline] [CrossRef]

47. Bowles EJ, Campbell KH, St John JC. Nuclear transfer: preservation of a nuclear genome at the expense of its associated mtDNA genome(s). Curr Top Dev Biol 2007; 77: 251-290. [Medline] [CrossRef]

48. Wallace DC. Mitochondrial diseases in man and mouse. Science 1999; 283: 1482 1488. [Medline] [CrossRef]

49. Wallace DC, Fan W. Energetics, epigenetics, mitochondrial genetics. Mitochondrion 2010; 10: 12-31. [Medline] [CrossRef] 